\title{
Overnight Monitoring of Turnover Movements in Parkinson’ s Disease Using A Wearable Three-Axis Accelerometer
}

Masashi Akamatsu ${ }^{*}$ Makoto Shiraishi, Kenji Uchino, Futaba Maki, Atsushi Tsuruoka, Shigeaki Tanaka, Daisuke Hara and Yasuhiro Hasegawa

Department of Internal Medicine, Division of Neurology, St. Marianna University School of Medicine, Kanagawa, Japan

*Corresponding author: Masashi Akamatsu, Department of Internal Medicine, Division of Neurology, St. Marianna University School of Medicine, Kanagawa, Japan, Tel: +81-44-977-8111; Fax: +81-44-976-8516 ; E-mail: shinnai@marianna-u.ac.jp

Rec date: Mar 15, 2016; Acc date: May 30, 2016; Pub date: June 2, 2016

Copyright: (c) 2016 Akamatsu M, et al. This is an open-access article distributed under the terms of the Creative Commons Attribution License, which permits unrestricted use, distribution, and reproduction in any medium, provided the original author and source are credited.

\begin{abstract}
Background: In patients with Parkinson's disease (PD), the impairment of voluntary and involuntary movement during sleep might affect their natural sleep and quality of life; however, there is no reliable method to evaluate turnover movements during sleep. We aimed to clarify whether overnight monitoring of turnover movements in bed using a wearable three-axis accelerometer is a feasible and reliable tool for evaluating the impact of motor complications during sleep in PD.
\end{abstract}

Methods: The number of turnover movements in bed was counted based on the graphic pattern in the X, Y, and $Z$ axis using threshold values in each axis to discriminate turnover movements from other movements mainly associated with respiration or cough. These threshold values were defined by the recordings of various turnover movements in normal volunteers. Overnight monitoring of turnover movements in bed from 9:00 pm to 7:00 am was performed in 7 normal volunteers and 5 patients (mean age, $76.4 \pm 4.6 \mathrm{yrs}$, Hoehn-Yahr stage, $3.6 \pm 0.5$; duration of disease, $8.8 \pm 5.6 \mathrm{yrs}$ ). In patients with PD, monitoring was performed before and after adjustment of anti-Parkinson medications.

Results: The number of turnover movements was significantly more restricted in PD before drug control than in control subjects $(p=0.005)$. The median number of overnight turnover movements increased from 0 to 5 times after drug control in patients with PD. The number of overnight turnover movements increased significantly in all 5 patients after adjusting their anti-Parkinson medications $(p=0.041)$.

Conclusion: Overnight monitoring of turnover movements in bed using a wearable three-axis accelerometer is feasible. Further studies are warranted to evaluate the impact of movement disorders during sleep on patients with PD.

Keywords: Parkinson's disease; Turnover movement; Wearable three-axis accelerometer

\section{Introduction}

Turnover movements in bed generally involve elevation of the upper limbs and their movement towards the shoulder, movements of the head and trunk, and raising of one leg [1]. In patients with Parkinson's disease, movement disorders during sleep might seriously affect their quality of life.

Disability in bed or adjusting bed clothes are evaluated in the Unified Parkinson's Disease Rating Scale (UPDRS) Part II [2], but these evaluations are based solely on patients' subjective answers. There is no reliable method to evaluate turnover movements during sleep, and no information is available about the impact of overnight movement disorders in handicapped patients, including those with Parkinson's disease.

Recently, a wearable three-axis accelerometer has been developed, with which acceleration or angular velocity can be continuously recorded for analysis of human motion, such as three-axis gait analysis in Parkinson's disease [3,4].
Our goal was to demonstrate the feasibility of evaluating overnight movement disorders using a wearable motion recorder equipped with three-axis acceleration sensors in patients with Parkinson's disease.

\section{Methods}

\section{Measurement of turnover movements in bed}

A wearable motion recorder $(75 \mathrm{~mm} \times 50 \mathrm{~mm} \times 20 \mathrm{~mm}, 120 \mathrm{~g})$ equipped with three-axis acceleration sensors (Mimamori-Gait system, MG-M1110-HW, LSI Medience Corporation, Tokyo, Japan) was used to record the motion from the three-axis acceleration data. The motion recorder was fixed on the centre of the abdomen at the navel using a special belt.

Three-axis acceleration data as shown in Figure 1 were collected 100 times a second and serially stored in the micro SD in the recorder through A/D conversion. These data were analysed offline using special commercially available software (MG-M1100-PC, LSI Medience Corporation). 


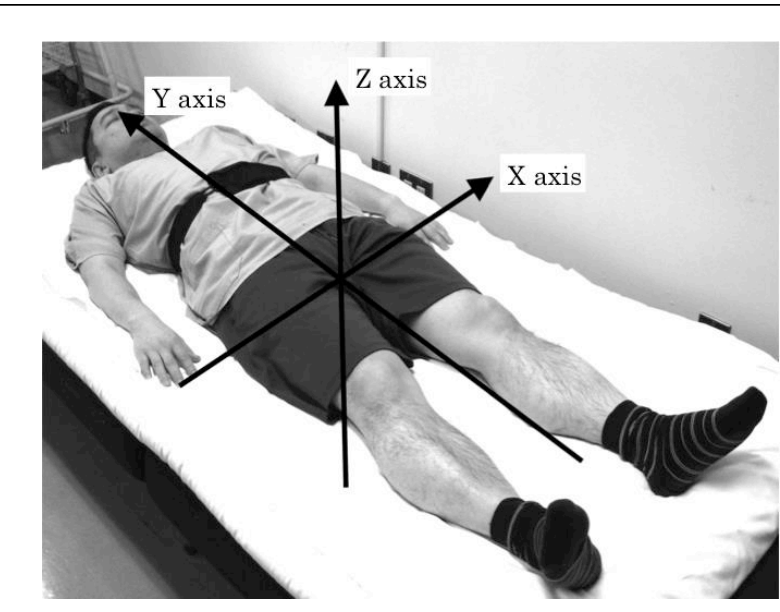

Figure 1: Axes for the measurement of three-dimensional acceleration.

$\mathrm{X}$ axis: from right to left, $\mathrm{Y}$ axis: from caudal to rostral, $\mathrm{Z}$ axis: from back to front.

Typical turnover movements in bed are shown in Figure 2. Because a turnover movement in bed is a movement around the $\mathrm{Y}$ axis, acceleration in the $\mathrm{Y}$ axis direction remains essentially zero. In the $90^{\circ}$ turnover movements, i.e., from supine to recumbent position, simultaneous changes in the $\mathrm{X}$ and $\mathrm{Z}$ axes are observed.

The graphic patterns can be useful to determine the direction of the turnover movements (Figures $2 \mathrm{~A}$ and $2 \mathrm{~B}$ ). The $\mathrm{Y}$ axis value maintained 1.0 gravity $(\mathrm{G})$ during sitting, standing, or walking.
A

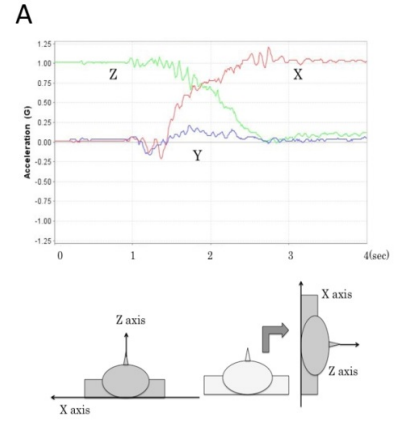

\section{B}

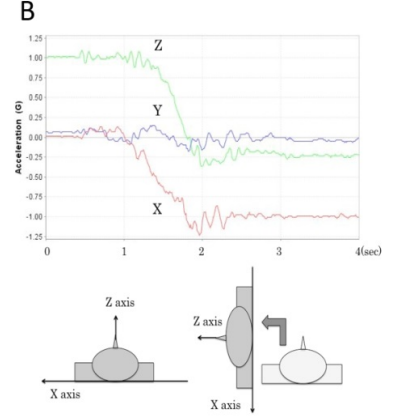

Figure 2: Diagnosis of body rotation.

It was confirmed that movement from the supine position to the right recumbent position is accomplished by the $\mathrm{Y}$ axis (body axis) remaining at baseline, with the loci of the $\mathrm{X}$ axis and $\mathrm{Z}$ axis crossing over each other simultaneously (A). Similarly, movement from the supine position to the left recumbent position can be diagnosed by the $\mathrm{Y}$ axis (body axis) remaining at baseline, with the loci of the $\mathrm{X}$ axis and $\mathrm{Z}$ axis both shifting downward simultaneously (B).

Once the turnover movement occurs, body position remains stable for a variable duration from a few minutes to hours which was defined as turnover interval. Therefore, turnover movements in bed can be counted based on the typical turnover movements followed by a stable period (Figure 3).
However, there is a great variation in the angle of each turnover movement, and slight drift may be observed because of the movement of the abdomen usually associated with respiration or cough. In this study, three-dimensional acceleration data were obtained in various turnover angles at $30^{\circ}, 60^{\circ}$, and $90^{\circ}$, in 7 normal volunteers (mean age, $28.6 \pm 2.4$ years old) to define cut-off values to discriminate turnover movements from noise.

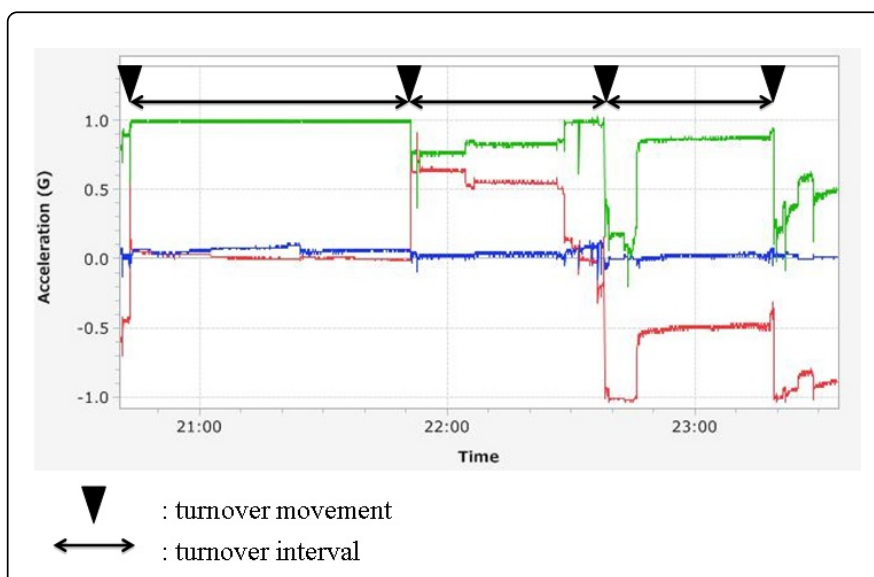

Figure 3: Measurement of turnover movements and turnover interval.

Turnover movements $(\boldsymbol{\nabla})$ and turnover interval $(\leftrightarrow)$ were measured on the display by expanding the time axis.

\section{Overnight monitoring}

Overnight monitoring of turnover movements in bed from 9:00 pm to 7:00 am was performed in the 7 normal volunteers (mean age, 62.1 \pm 21.7 years old) and 5 patients with Parkinson's disease (mean age, $77.0 \pm 3.5$ years old; Hoehn-Yahr stage, $3.8 \pm 0.4$, duration of disease, $10.6 \pm 5.2 \mathrm{yrs})$. Then, the number of turnover movements in each recording was calculated, and total bed resting time (minutes) was also calculated by defining the $\mathrm{Y}$ axis value as $<0.324$. Parkinson's disease was diagnosed according to the United Kingdom Parkinson's disease Society Brain Bank clinical diagnostic criteria [5].

All patients responded well to dopamine replacement therapy. All monitoring was performed during hospital admission. After completion of overnight monitoring, additional anti-Parkinson medication was started for two to four weeks to control their movement disorders. Then, the overnight monitoring was repeated to assess the effects of treatment on turnover movements in bed. Additional doses of anti-Parkinson medication were expressed as levodopa equivalent doses [6].

All study protocols were approved by the Bioethics Committee of St. Marianna University School of Medicine. Informed consent to participate in the investigation was obtained from all participants after explaining the purposes of the study.

\section{Statistical Analyses}

The characteristics of the subjects are given as means and standard deviation (SD), unless otherwise indicated. The Wilcoxon signed-rank test and the Mann-Whitney test were used for data that were not normally distributed. Values of $\mathrm{p}<0.05$ were considered significant. All 
Citation: Akamatsu M, Shiraishi M, Uchino K, Maki F, Tsuruoka A, et al. (2016) Overnight Monitoring of Turnover Movements in Parkinson's Disease Using A Wearable Three-Axis Accelerometer. J Neurol Disord 4: 267. doi:10.4172/2329-6895.1000267

Page 3 of 5

statistical analyses were performed using SPSS version 21 (IBM SPSS Statistics for Windows; IBM Corp, Armonk, NY).

\section{Results}

\section{Turnover movements in normal volunteers}

Recording of turnover movements in bed at $30^{\circ}, 60^{\circ}$, and $90^{\circ}$ was performed using a wearable three-axis accelerometer in 7 normal volunteers. Each session consisted of 5 recordings. The mean values and $95 \%$ range of acceleration values for the 3 axes are shown in Table 1. Based on the highest value of the range in the $\mathrm{Y}$ axis, the threshold value of $<0.324 \mathrm{G}$ was adopted as the requirement for resting in bed.

While the $\mathrm{Y}$ axis value remained below $0.324 \mathrm{G}$, turnover movement was defined as the presence of simultaneous changes in both $\mathrm{X}$ and $\mathrm{Z}$ axes of at least $0.580 \mathrm{G}$ and $0.200 \mathrm{G}$, respectively, for further studies of overnight monitoring.

\begin{tabular}{|c|c|c|c|}
\hline \multirow{2}{*}{ Turnover Angle } & \multicolumn{3}{|c|}{ Acceleration Change (G, Absolute Value) } \\
\cline { 2 - 4 } & \multicolumn{3}{|c|}{ M5\% Range) } \\
\cline { 2 - 4 } & X-axis & Y-axis & Z-axis \\
\hline \multirow{2}{*}{$30^{\circ}$} & 0.74 & 0.178 & 0.35 \\
\cline { 2 - 4 } & $(0.580-0.900)$ & $(0.089-0.267)$ & $(0.200-0.500)$ \\
\hline \multirow{2}{*}{$60^{\circ}$} & 0.932 & 0.189 & 0.623 \\
\cline { 2 - 4 } & $(0.828-1.036)$ & $(0.086-0.292)$ & $(0.443-0.803)$ \\
\hline \multirow{2}{*}{$90^{\circ}$} & 1.113 & 0.245 & 1.158 \\
\cline { 2 - 4 } & $(1.014-1.212)$ & $(0.166-0.324)$ & $(0.958-1.362)$ \\
\hline
\end{tabular}

Table 1: Acceleration changes in turnover movements of 7 control subjects.

\section{Overnight monitoring}

The numbers of turnover movements and turnover intervals in 7 normal volunteers during a 10-hour monitoring period from 9:00 pm to 7:00 am are shown in Table 2 and a typical overnight recording in a normal volunteer is shown in Figure 4. Total bed resting time varied from 364 minutes to 596 minutes. Total number of turnover movement during the bed resting time also varied from 4 times to 49 times.

\begin{tabular}{|l|l|l|l|l|l|l|}
\hline Case & Age & Sex & $\begin{array}{l}\text { Total bed } \\
\text { resting } \\
\text { time } \\
\text { (minute) }\end{array}$ & $\begin{array}{l}\text { Total } \\
\text { number of } \\
\text { turnover } \\
\text { movement }\end{array}$ & $\begin{array}{l}\text { Median of } \\
\text { turnover } \\
\text { interval } \\
\text { (second) }\end{array}$ & $\begin{array}{l}\text { Total time } \\
\text { of } \\
\text { standing } \\
\text { or sitting } \\
\text { position } \\
\text { (minute) }\end{array}$ \\
\hline 1 & 29 & M & 364 & 9 & $\begin{array}{l}1013 \\
(9-2794)\end{array}$ & 236 \\
\hline 2 & 28 & M & 546 & 49 & $\begin{array}{l}232 \\
(3-3128)\end{array}$ & 54 \\
\hline 3 & 79 & M & 530 & 19 & $\begin{array}{l}771 \\
(225-3153)\end{array}$ & 70 \\
\hline 4 & 73 & $\mathrm{~F}$ & 579 & 27 & $\begin{array}{l}714 \\
(180-2908)\end{array}$ & 21 \\
\hline
\end{tabular}

\begin{tabular}{|l|l|l|l|l|l|l|}
\hline 5 & 78 & $\mathrm{M}$ & 545 & 4 & $\begin{array}{l}2672.5 \\
(1075-14113 \\
)\end{array}$ & 55 \\
\hline 6 & 74 & $\mathrm{M}$ & 566 & 36 & $\begin{array}{l}390 \\
(1-2876)\end{array}$ & 34 \\
\hline 7 & 78 & $\mathrm{~F}$ & 596 & 24 & $\begin{array}{l}845 \\
(6-5144)\end{array}$ & 4 \\
\hline \multicolumn{7}{|l|}{ * } \\
\hline \multicolumn{7}{|l|}{ values (minimum-maximum). } \\
\hline
\end{tabular}

Table 2: Parameters of turnover movements in control subjects.

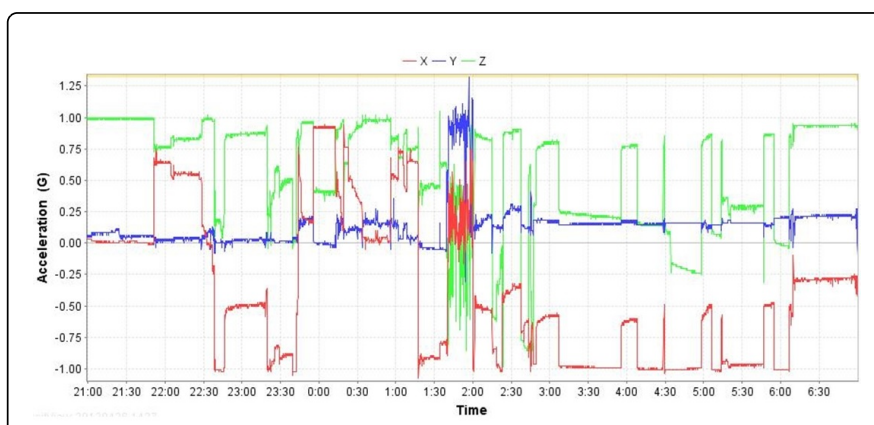

Figure 4: Overnight recording of three-axis acceleration in a normal volunteer.

A 73-year-old woman, a total of 27 turnover movements are observed during the 10-hour recording period.

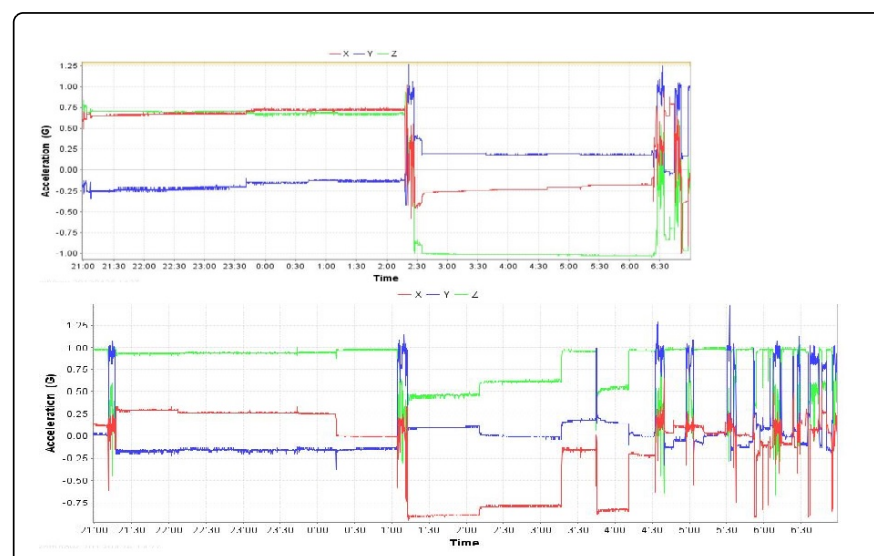

Figure 5: A 77-year-old patient with Parkinson's disease (Case \#4 showing the three-axis locus chart before and after drug control). Overnight monitoring of a Parkinson's disease patient with a levodopa equivalent dose of $450 \mathrm{mg} /$ day, Hoehn \& Yahr Stage 4, duration of disease: 3 years, 77-year-old woman (Table 3, Case \#4). Figure $5 \mathrm{~A}$ shows the three-axis locus chart before drug control, and Figure 5B shows the locus chart after drug control. An increase in the number of turnover movements from before drug control (3 times, LVED $450 \mathrm{mg}$ ) to after drug control (5 times, LVED $600 \mathrm{mg}$ ) is seen.

The total bed rest times were similar among the control subjects (median; 546 minutes, min.-max.; 364-596 minutes) and patients with Parkinson's disease before (median; 568 minutes, min.-max.; 427-598 minutes) and after the drug control (median; 556 minutes, min.-max.; 
480-557 minutes). Numbers of turnover movements in patients with Parkinson's disease before and after the drug control were significantly fewer than that in the normal volunteers, $p=0.005$ and $p=0.018$ respectively (Mann-Whitney test Figure 6). The number of overnight turnover movements in patients with Parkinson's disease increased significantly after drug control $(\mathrm{p}=0.041$, Wilcoxon signed-rank test, Figure 6).

\begin{tabular}{|c|c|c|c|c|c|c|c|c|c|c|}
\hline \multirow[t]{3}{*}{ Case } & \multirow[t]{3}{*}{ Age } & \multirow[t]{3}{*}{ Sex } & \multirow{3}{*}{$\begin{array}{l}\text { Disease } \\
\text { Durations } \\
\text { (yr) }\end{array}$} & \multirow[t]{3}{*}{ Hoehn-Yahr } & \multirow{2}{*}{\multicolumn{2}{|c|}{$\begin{array}{l}\text { Levodopa equivalent dose } \\
\text { (mg) }\end{array}$}} & \multirow{2}{*}{\multicolumn{2}{|c|}{$\begin{array}{l}\text { Number of turnover } \\
\text { movements }\end{array}$}} & \multirow{2}{*}{\multicolumn{2}{|c|}{$\begin{array}{l}\text { Bed resting time } \\
\text { (minutes) }\end{array}$}} \\
\hline & & & & & & & & & & \\
\hline & & & & & Before & After & Before & After & Before & After \\
\hline 1 & 80 & M & 17 & 4 & 0 & 1116 & 0 & 7 & 573 & 556 \\
\hline 2 & 68 & $M$ & 4 & 3 & 660 & 820 & 0 & 2 & 598 & 557 \\
\hline 3 & 76 & M & 6 & 3 & 0 & 420 & 8 & 9 & 459 & 543 \\
\hline 4 & 77 & $\mathrm{~F}$ & 3 & 4 & 450 & 600 & 3 & 5 & 568 & 556 \\
\hline 5 & 81 & $\mathrm{~F}$ & 14 & 4 & 1400 & 1535 & 0 & 1 & 427 & 480 \\
\hline
\end{tabular}

Table 3: Change in number of turnover movements in patients with Parkinson's disease before and after drug control.

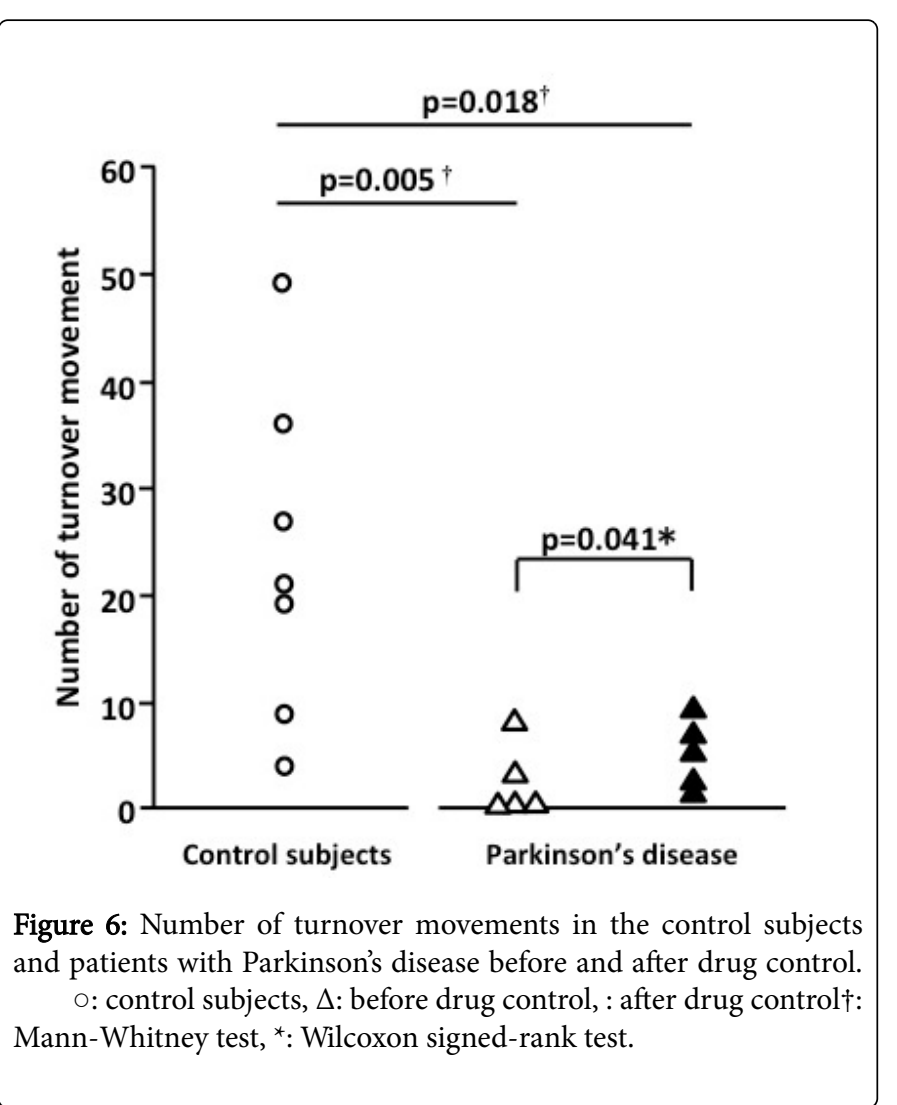

\section{Discussion}

Our study demonstrated that the overnight monitoring of turnover movements using a wearable three-axis accelerometer is feasible. Turnover movements are complex, and although not all turnover movements with various rotational angles are captured, with the present method, at least the turnover movements determined by a change in the accelerometer that records a turnover movement of $\geq 30^{\circ}$ are captured. Numbers of turnover movements in normal volunteers varied from 4 to 49 , implying that cut-off value for the diagnosis of abnormally restricted turnover movements could not be determined. However, the patients with Parkinson's disease (Hoehn and Yahr stages III to IV) in the present study made significantly fewer turnover movements at night than healthy individuals. It is of great importance that no turnover movement was observed in three patients with advanced Parkinson's disease (Hoehn-Yahr stage IV) and turnover movements were recorded after the adjustment of anti-Parkinson medications. Our methods could be utilized to improve motor complications during sleep in patients with advanced Parkinson's disease.

Previous research on turnover movements reported that rotational movement in the Y-axis was poor in tetraplegic patients, and turnover movements were difficult in patients with bradykinesia caused by extrapyramidal damage [7]. Moreover, muscle spindles are abundantly distributed in the sub-occipital muscle groups [8], and we expected that, in Parkinson's disease patients, there would be not only impaired bending of the neck due to rigidity of the sub-occipital muscle groups, but also greater tension in the back muscles, which would hinder flexible movement of the spinal cord and make turnover movements difficult. The presence of glenohumeral rhythm across the entire movable region is also essential for movement of the shoulder joint complex [9]. Thus, we predicted that establishing the rhythm for the turnover movements would also be impaired in Parkinson's disease patients. Therefore, capturing turnover movements as representing the status of overnight turnover movements can become a new method for evaluating movement disorders in Parkinson's disease patients.

The present study had several limitations. First, research has shown that there is considerable variation in turnover movements [1], and that there is a bimodal component of either $\leq 10$ seconds or $\geq 100$ seconds in the turnover movements of healthy individuals, but these components disappear in patients with neurodegenerative conditions [10]. Further studies are needed to investigate whether our method of capturing and measuring turnover movements as simple body-axis rotational movements can accurately quantify and serve as a clinically significant evaluation of night-time movement disorders. Second, this study had a small sample size, potentially resulting in insufficient power to detect significant differences. 
Citation: Akamatsu M, Shiraishi M, Uchino K, Maki F, Tsuruoka A, et al. (2016) Overnight Monitoring of Turnover Movements in Parkinson's Disease Using A Wearable Three-Axis Accelerometer. J Neurol Disord 4: 267. doi:10.4172/2329-6895.1000267

Page 5 of 5

In conclusion, the present study demonstrated that overnight monitoring of turnover movements in bed by a wearable three-axis accelerometer is feasible. This method could be used to evaluate the impact of movement disorders during sleep on patients with Parkinson's disease.

\section{References}

1. Richter RR, Van Sant AF, Newton RA (1989) Description of adult rolling movements and hypothesis of developmental sequences. Phys Ther 69: 63-71.

2. Goetz CG, Tilley BC, Shaftman SR (2007) Movement Disorder Societysponsored revision of the Unified Parkinson's Disease Rating Scale (MDSUPDRS): process, format, and clinimetric testing plan. Mov Disord 22: 41-47.

3. Utsumi H, Terashi H, Ishimura Y, Takazawa T, Hayashi A, et al. (2012) Quantitative assessment of gait bradykinesia in Parkinson's disease using a portable gait rhythmogram. Acta Med Okayama 66: 31-40.

4. Mitoma H, Yoneyama M, Orimo S (2010) 24-hour recording of Parkinsonian gait using a portable gait rhythmogram. Intern Med 49: 2401-2408.
5. Gibb WR, Lees AJ (1988) The relevance of the Lewy body to the pathogenesis of idiopathic Parkinson's disease. J Neurol Neurosurg Psychiatry 51: 745-752.

6. Tomlinson CL, Stowe R, Patel S, Rick C, Gray R, et al. (2010) Systematic review of levodopa dose equivalency reporting in Parkinson's disease. Mov Disord 25: 2649-2653.

7. Tanaka S, Yoshimura O, Kobayashi R, Minematsu A, Sasaki H, et al. (2000) Three-dimensional measurement of rolling in tetraplegic patients. Spinal Cord 38: 683-686.

8. Cooper S, Daniel PM (1963) Muscle spindles in man; their morphology in the lumbricals and the deep muscles of the neck. Brain 86: 563-586.

9. Cailliet R (1980) The shoulder in hemiplegia. Philadelphia: PA, F.A. Davis \& Co. p: 89-120.

10. Yoneyama M, Okuma Y, Utsumi H, Terashi H, Mitoma H (2014) Human turnover dynamics during sleep: statistical behavior and its modeling. Phys Rev E Stat Nonlin Soft Matter Phys 89: 032721. 